OPEN ACCESS

Edited by:

Michael R. Gold,

University of British Columbia, Canada

Reviewed by:

Goetz Ehrhardt,

University of Toronto, Canada

Spencer Gibson,

University of Manitoba, Canada

*Correspondence:

Harald Kolmar

Harald.Kolmar@TU-Darmstadt.de

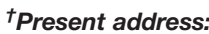

Julius Grzeschik,

Biologics Technology and

Development, Ferring

Pharmaceuticals Darmstadt

Laboratory, TU Darmstadt,

Darmstadt, Germany

${ }^{\text {F}}$ These authors have contributed equally to this work

Specialty section:

This article was submitted to B Cell Biology,

a section of the journal

Frontiers in Immunology

Received: 08 May 2020 Accepted: 02 November 2020 Published: 26 November 2020

Citation:

Macarrón Palacios A, Grzeschik J,

Deweid L, Krah S, Zielonka S,

Rösner T, Peipp M, Valerius $T$ and Kolmar H (2020) Specific Targeting of Lymphoma Cells Using Semisynthetic Anti-Idiotype Shark Antibodies.

Front. Immunol. 11:560244. doi: 10.3389/fimmu.2020.560244

\section{Specific Targeting of Lymphoma Cells Using Semisynthetic Anti- Idiotype Shark Antibodies}

\author{
Arturo Macarrón Palacios ${ }^{1 \neq}$, Julius Grzeschik ${ }^{1+\neq}$, Lukas Deweid ${ }^{1}$, Simon Krah ${ }^{1}$, \\ Stefan Zielonka ${ }^{1}$, Thies Rösner ${ }^{2}$, Matthias Peipp ${ }^{2}$, Thomas Valerius ${ }^{2}$ and Harald Kolmar ${ }^{1 *}$ \\ ${ }^{1}$ Institute for Organic Chemistry and Biochemistry, Technische Universität Darmstadt, Darmstadt, Germany, ${ }^{2}$ Division of \\ Stem Cell Transplantation and Immunotherapy, Department of Medicine II, UKSH, CAU Kiel, Kiel, Germany
}

The B-cell receptor (BCR) is a key player of the adaptive immune system. It is a unique part of immunoglobulin (lg) molecules expressed on the surface of B cells. In case of many Bcell lymphomas, the tumor cells express a tumor-specific and functionally active BCR, also known as idiotype. Utilizing the idiotype as target for lymphoma therapy has emerged to be demanding since the idiotype differs from patient to patient. Previous studies have shown that shark-derived antibody domains (vNARs) isolated from a semi-synthetic CDR3-randomized library allow for the rapid generation of anti-idiotype binders. In this study, we evaluated the potential of generating patient-specific binders against the idiotype of lymphomas. To this end, the BCRs of three different lymphoma cell lines SUP-B8, Daudi, and IM-9 were identified, the variable domains were reformatted and the resulting monoclonal antibodies produced. The SUP-B8 BCR served as antigen in fluorescence-activated cell sorting (FACS)-based screening of the yeast-displayed vNAR libraries which resulted after three rounds of screening in the enrichment of antigen-binding vNARs. Five vNARs were expressed as Fc fusion proteins and consequently analyzed for their binding to soluble antigen using biolayer interferometry (BLI) revealing binding constants in the lower single-digit nanomolar range. These variants showed specific binding to the parental SUP-B8 cell line confirming a similar folding of the recombinantly expressed proteins compared with the native cell surface-presented BCR. First initial experiments to utilize the generated vNAR-FC variants for BCR-clustering to induce apoptosis or ADCC/ADCP did not result in a significant decrease of cell viability. Here, we report an alternative approach for a personalized B-cell lymphoma therapy based on the construction of vNAR-Fc antibody-drug conjugates to enable specific killing of malignant $\mathrm{B}$ cells, which may widen the therapeutic window for B-cell lymphoma therapy.

Keywords: B-cell receptor, idiotype, lymphoma, yeast display, vNAR, antibody-drug conjugate 


\section{INTRODUCTION}

In recent years, monoclonal antibodies have emerged as therapeutics with exceptional relevance for inflammatory and infectious diseases and the treatment of cancer (1). The number of antibodies in late-stage clinical trials has substantially increased to over 50 in the year 2017. Furthermore, in this year the number of novel antibody therapeutics that were approved in either United States or the European Union reached double-digit numbers for the first time (2). Being approved in 1997, the monoclonal antibody (mAb) Rituximab was the first FDA approved $\mathrm{mAB}$ specifically for cancer treatment and was for a long time the most sold biologic drug in clinical oncology. Rituximab is active in a diversity of human lymphomas and chronic lymphocytic leukemia (3). Rituximab is a chimeric $\mathrm{mAB}$ targeting the $\mathrm{CD} 20$ antigen present on both healthy B cells as well as on most B-cell lymphomas.

Today $5 \%$ of all newly diagnosed malignancies are lymphoma-related (4). More than $90 \%$ of adult lymphomas are mature B-cell non-Hodgkin lymphomas (B-NHL), with a large variety of histological subtypes (5). Besides Rituximab, a plethora of different small molecules and mAbs have been developed that either target different CD20 epitopes (for instance ofatumumab and obinutuzumab) or other B-cell specific antigens as CD19, $\mathrm{CD} 22$, and $\mathrm{CD} 30$ (6-10). For B-cell targeting with increased efficacy, the effect of antibody-drug conjugates (ADCs) has been analyzed in clinical trials (11). The mentioned different antibody therapies share the characteristic of targeting $B$ cells in a nonspecific manner. CD20 and other potential surface markers are present on $\mathrm{B}$ cells regardless of the targeted cell being malignant or not. Thus, all of the approved therapeutics can lead to severe side effects (12). As a consequence, the specific targeting of tumor cells might emerge as beneficial for lymphoma therapies $(13,14)$.

Most B-cell lymphomas express a cell surface immunoglobulin molecule referred to as $\mathrm{B}$-cell receptor (BCR). The $\mathrm{BCR}$ consists of a membrane-anchored immunoglobulin (Ig) associated with transmembrane proteins. The extracellular region of the BCR is an antibody normally serving as recognition site for foreign antigens (15). It has a crucial role in signaling after first encounter of a B cell with its cognate antigen. Here, the BCR mediates antigen internalization and the subsequent presentation of peptides to Thelper cells. This results in triggering of cell proliferation, differentiation and the generation of memory B cells and antibody-secreting B cells (16).

In general, B-cell lymphomas develop from clonal populations of precursor B cells in different stages of B-cell

\footnotetext{
Abbreviations: ADC, antibody-drug conjugate; ADCC, antibody-dependent cellular cytotoxicity; ADCP, antibody-dependent cellular phagocytosis; Aga2p, $a$-agglutinin II subunit; APC, antigen-presenting cell; BCR, B-cell receptor; BLI, biolayer interferometry; BSA, bovine serum albumin; ELISA, enzyme-linked immunosorbent assay; CDR, complementarity-determining region; Fab, antigen-binding fragment; FACS, fluorescence-activated cell sorting; GPI, glycosylphosphatidyl-inositol; Id, idiotype; Ig, immunoglobulin; KB, kinetics buffer; mAb, monoclonal antibodies; MMAE, monomethyl auristatin E; PBMCs, peripheral blood mononuclear cells; PBS, phosphate-buffered saline; PCR, polymerase chain reaction.
}

differentiation. Consequently, the BCR is different for each lymphoma patient since variable regions of BCRs are generated by random rearrangement of germ line immunoglobulin genes (17). During malignant transformation of a $\mathrm{B}$ cell, each cell of the formed clonal population expresses the same unique BCR, the so-called idiotype (Id).

Specific binding can not only be utilized for specific cellular targeting but also for induction of anergy and clonal deletion of lymphoma cells. This occurs when B-cells perceive a BCR stimulus in the absence of T-cell help (18), Toll-like receptor binding or cytokine signals from accessory cells (19). Consequently, the BCR might act as a tumor-specific and functionally active cell surface marker able to trigger apoptosis.

Previous studies have shown the general applicability of mAbs directed against the patient-specific Ids in lymphoma studies (20). Although these studies have confirmed the safe administration and positive immunological effects in-vivo, the strategy of Id-targeting has not emerged as a widespread therapy for lymphomas until now. The most important limiting factor was the requirement to generate tailor-made $\mathrm{mAbs}$ for every single patient. Since the application of classical hybridoma technology (21) for producing individualized mAbs was not feasible in a cost-effective process, this strategy was not further investigated extensively in the following years. The group of Ron Levy, one of the pioneers of anti-Id mAbs for lymphoma treatment $(20,22)$, brought the issue of anti Id-mAbs back on the agenda: They published a new concept for patientspecific lymphoma targeting based on anti-Id peptides in 2016 (23).

The respective peptides specifically recognizing the BCR were identified by screening a phage-display library (24), chemically synthesized, and then coupled chemically to the amino terminus of a premade IgG Fc protein. They clearly demonstrated the specific recognition of tumor cells in vitro, confirmed the triggering of tumor cell apoptosis and phagocytosis by macrophages, and effectively cleared human lymphoma cells in a murine xenograft model. However, utilizing peptides for specific BCR-binding might have some drawbacks, for example a short half-life in-vivo and their significant unspecific binding after administration that might occur. To evaluate alternatives to this strategy, we decided to use shark-derived antibody fragments for the generation of antiId binders.

Compared to conventional antibodies from mammals, cartilaginous fish like sharks have a unique form of heavy chainonly antibodies, termed immunoglobulin new antigen receptor (IgNAR) (25). Molecules of this type are devoid of any light chain but possess heavy chains comprised of five constant domains followed by the variable domain (vNAR) that is exclusively responsible for antigen binding. Since vNARs lack the hydrophobic $\mathrm{V}_{\mathrm{H}}-\mathrm{V}_{\mathrm{L}}$ interface of a conventional antibody, they are reported to have an increased water solubility $(26,27)$. Furthermore, vNARs only possess two (CDR1 and CDR3) CDR loops leading to the fact that vNARs, with a size of 11 to $12 \mathrm{kDa}$, are the smallest antigenbinding antibody-like domain in the animal kingdom (28). Of note, the elongated CDR3 loop primarily mediating antigen-binding is at least partly able to compensate for the lack of the CDR2 loop. 
Additionally, it is reported that vNARs, based on their elongated CDR3 loop, are able to interact with hidden, cleft-like epitopes not able to be recognized by conventional antibodies. Besides the isolation of vNARs directed against therapeutically relevant target proteins as TNF $\alpha$ (29), the malaria-related AMA protein (30) or EpCAM (31), it has been shown that vNARs can be engineered towards $\mathrm{pH}$-sensitive antigen-binding (32) for application in biotechnological applications. Recently, it was shown that screening of semi-synthetic and CDR3-randomized vNAR libraries in combination with yeast surface display allows for the fast and convenient identification of anti-idiotypic vNAR domains directed against the paratope of mAbs (33). The resulting anti-idiotypic vNAR variants were not cross-reactive towards unrelated antibodies and retained their excellent target recognition in the presence of human and murine serum.

Based on these experimental experiences, we investigated in this study whether this strategy can also be applied to the isolation of anti-idiotype vNARs specifically recognizing the BCR of lymphoma cell lines and finally inducing cell death (Figure 1). Here we show that yeast library screening for vNARs directed against soluble BCR SUP-B8 lymphoma cells results in anti-idiotype vNARs showing specific receptor binding. Since we could not observe the induction of apoptosis via clustering of BCR molecules in first initial experiments, we developed an alternative approach by generating vNAR antibody-drug conjugates that induced specific killing in lymphoma cells at low nanomolar concentrations.

\section{MATERIALS AND METHODS}

Experiments with human effector cells were approved by the Ethics Committees of the participating institutions in accordance with the Declaration of Helsinki.

\section{Cell Lines, RNA Isolation, and cDNA Synthesis}

Three immunoglobulin expressing lymphoma cell lines Daudi, IM-9, and SUP-B8 (obtained from the group of Prof. Ron Levy) were used for idiotype cloning. Daudi and IM- 9 cells were grown in RPMI-1640 medium with 10\% FBS and $2 \mathrm{mM}$ glutamine. SUP-B8 cells were treated the same way except using 15\% FBS for cultivation. Extraction of total RNA from $1 \times 10^{7}$ human lymphoma cells was carried out after cell homogenization with QIAshredder (Qiagen) using the commercially available kit RNeasy Minikit (Qiagen) according to the supplier's protocol. Subsequently, cDNA-synthesis was carried out using $50 \mu \mathrm{l}$ RNA extract, $10 \mu \mathrm{l}$ random hexamer primers $(50 \mathrm{ng} / \mu \mathrm{l}), 10 \mu \mathrm{l} 50 \mu \mathrm{M}$ dNTPs, $30 \mu \mathrm{H}_{2} \mathrm{O}, 40 \mu \mathrm{l} 25 \mathrm{mM} \mathrm{MgCl}_{2}, 20 \mu \mathrm{l} 10 \times$ RT-buffer, $20 \mu \mathrm{l} 0.1 \mathrm{M}$ DTT, $10 \mu \mathrm{l}$ RNase OUT, and $10 \mu \mathrm{l}$ SuperScript III reverse transcriptase (all components acquired from SuperScript III First-Strand Kit, Thermo Fisher Scientific). Incubation for $5 \mathrm{~min}$ at $25^{\circ} \mathrm{C}$ was followed by incubation for $60 \mathrm{~min}$ at $50^{\circ} \mathrm{C}$ and an inactivation step at $85^{\circ} \mathrm{C}$ for $5 \mathrm{~min}$. Subsequently, $1 \mu \mathrm{l}$ $\mathrm{RNAaseH}$ was added and the reaction was incubated for $20 \mathrm{~min}$ at $37^{\circ} \mathrm{C}$. The synthesized cDNA was stored at $-20^{\circ} \mathrm{C}$.

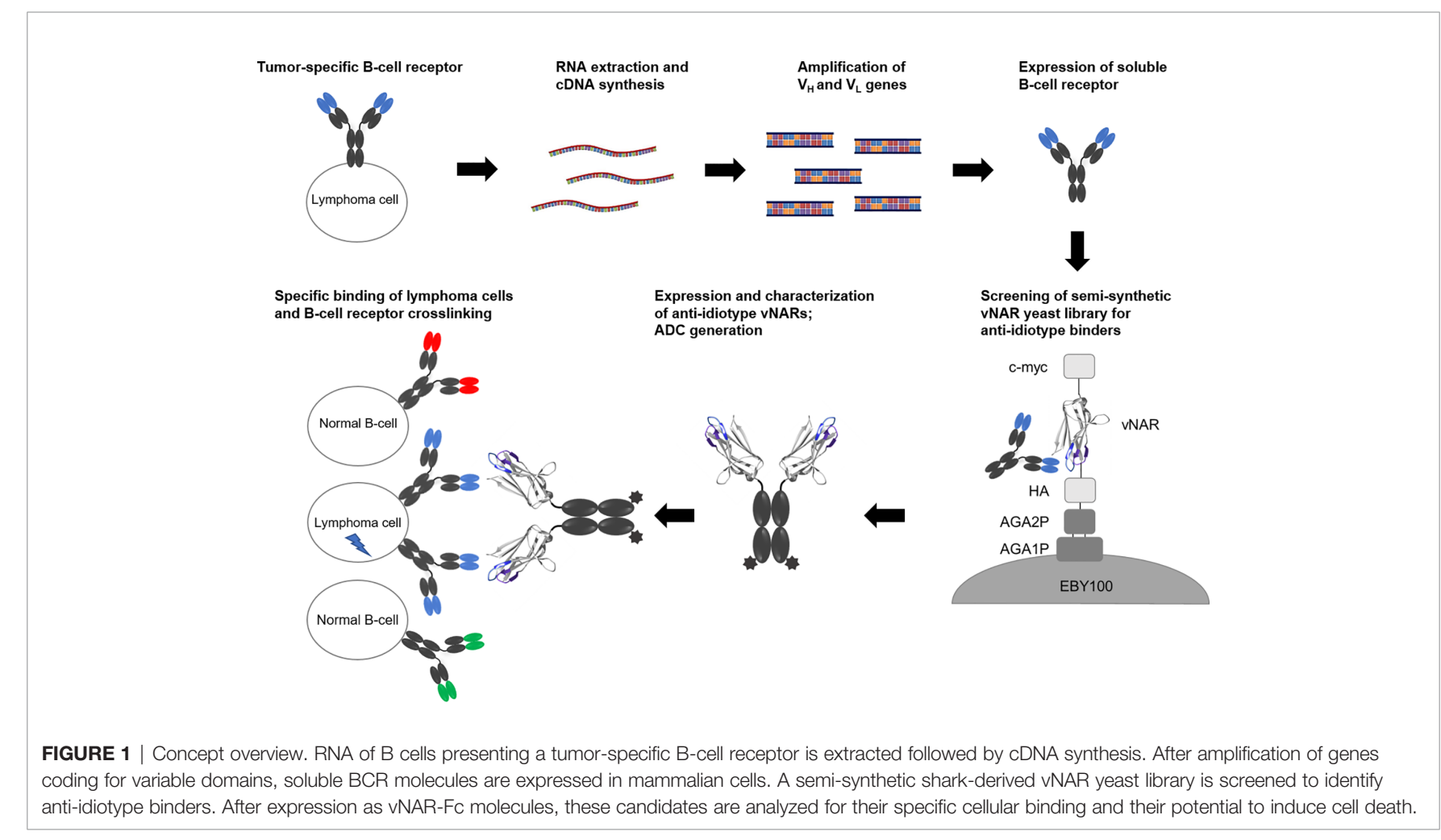




\section{Expression of Soluble B-Cell Receptors}

Variable antibody regions were amplified from cDNA in two different PCR reactions using Taq or Q5 Polymerase (NEB) in a reaction volume of $100 \mu \mathrm{l}$. For each cell line and chain, the reactions were prepared using 1 to $2 \mu \mathrm{l}$ cDNA. Amplification of $\mathrm{V}_{\mathrm{H}}$ and $\mathrm{V}_{\mathrm{L}}$ genes was carried out using the primers listed in Tab. S1. A detailed overview about the amplification strategy can be found in a publication by Maleshko et al. (34). For all reactions the following conditions were set: $95^{\circ} \mathrm{C}$ for $30 \mathrm{~s}, 30$ cycles of $20 \mathrm{~s}$ at $95^{\circ} \mathrm{C}, 30 \mathrm{~s}$ at $57^{\circ} \mathrm{C}$, and $30 \mathrm{~s}$ at $68^{\circ} \mathrm{C}$, followed by $68^{\circ} \mathrm{C}$ for $5 \mathrm{~min}$. PCR products were purified via Wizard $^{\circledR}$ SV Gel and PCR Clean-up System (Promega). Afterwards PCR products were sent for sequencing by the company Seqlab. For cloning of $\mathrm{B}$-cell receptors of all used cell line $\mathrm{V}_{\mathrm{H}}$ genes were amplified using primers introducing restriction sites for $B a m \mathrm{HI}$ and ApaI (Daudi_HC_BamHI_up/IM9_HC_BamHI_up/SUPB8_ HC_BamHI_up and Daudi_HC_ApaI_lo/IM9_HC_ApaI_lo/ SUPB8_HC_ApaI_lo). For light chain cloning of Daudi and IM9 cell lines $V_{L}$ genes and the $C_{\kappa}$ domain were amplified separately utilizing the primers Daudi_LC_BamHI_up/IM9_LC_BamHI_up and Daudi_LC_SOE_LO/IM9_LC_SOE_LO for $V_{L}$ genes on the one hand and Daudi_LC_SOE_UP/IM9_LC_SOE_UP with LC_kappa_NotI_lo for $\mathrm{C}_{\kappa}$ on the other hand. For the latter reaction a vector bearing the coding sequence for Matuzumab kappa light chain served as template. Afterwards fusion PCR was performed using the primer pair IM9_LC_up/ Daudi_LC_up and LC_kappa_NotI_lo. $20 \mathrm{ng}$ of each domain was amplified using Taq polymerase for 15 cycles without addition of oligonucleotides with an elongation time of $50 \mathrm{~s}$. Subsequently, 15 PCR cycles were performed after addition of oligonucleotides. Afterwards the products were purified via Wizard ${ }^{\circledR}$ SV Gel and PCR Clean-up System. Light chain of SUPB8 was constructed in a similar way: After separate amplification of $\mathrm{V}_{\mathrm{L}}$ genes using the primers SUPB8_LC_BamHI_up and SUPB8_LC_SOE_lo and the $C_{\lambda}$ domain using the oligonucleotides SUPB8_LC_ SOE_up and SUPB8_Lambda_NotI_lo. For the latter reaction the vector PYD_lambda_constant with the coding sequence for lambda light chain served as template. Subsequent fusion PCR and purification was performed according to the generation of Daudi and IM9 light chains. Restriction of PCR products and vectors pTT5-hu425H/pTT5-hu425L (NRC Biotechnology Research Institute) with the respective restriction enzymes was followed by ligation and transformation into Escherichia coli strain $\mathrm{DH} 5 \alpha$. After incubation overnight plasmids were isolated using the PureYield ${ }^{\mathrm{TM}}$ Plasmid Miniprep System (Promega) followed by sequence verification. After that Expi293F ${ }^{\mathrm{TM}}$ cells were transiently transfected using polyethyleneimine (Polysciences) according to the instructions of the manufacturer (Thermo Fisher Scientific). After 5 days the respective culture supernatants were harvested, sterile-filtered (0.22 $\mu \mathrm{m}$ Filtropur S 0.2, Sarstedt) and purified using HiTrap Protein A HP columns (GE Healthcare) in combination with an ÄKTA purification system (GE Healthcare). This was followed by buffer exchange via dialysis against PBS using a membrane with a MWCO $\sim 14 \mathrm{kDa}$. The purified proteins were stored at $-80^{\circ} \mathrm{C}$.

\section{Yeast Strains, Media, and Reagents}

Saccharomyces cerevisiae strain EBY100 was utilized for yeast surface display (35). YPD medium was composed of $20 \mathrm{~g} / \mathrm{L}$ dextrose, $20 \mathrm{~g} / \mathrm{L}$ tryptone, and $10 \mathrm{~g} / \mathrm{L}$ yeast extract. SD-CAA medium was prepared using $8.6 \mathrm{~g} / \mathrm{L} \mathrm{NaH}{ }_{2} \mathrm{PO}_{4} \times \mathrm{H}_{2} \mathrm{O}, 5.4 \mathrm{~g} / \mathrm{L} \mathrm{Na} \mathrm{HPO}_{4}, 1.7 \mathrm{~g} / \mathrm{L}$ yeast nitrogen base without amino acids, $5 \mathrm{~g} / \mathrm{L}$ ammonium sulphate, $5 \mathrm{~g} / \mathrm{L}$ bacto casamino acids, and $20 \mathrm{~g} / \mathrm{L}$ dextrose. SG-CAA medium was prepared the same way except for the substitution of glucose sugar with galactose. Phosphate-buffered saline (PBS) was prepared with 8.1 g/L NaCl, $1.13 \mathrm{~g} / \mathrm{L} \mathrm{Na}_{2} \mathrm{HPO}_{4}, 0.75 \mathrm{~g} / \mathrm{L} \mathrm{KCl}$, and $0.27 \mathrm{~g} / \mathrm{L} \mathrm{KH}_{2} \mathrm{PO}_{4}$.

\section{Yeast Library Construction}

The generation of semi-synthetic vNAR yeast display libraries was extensively described by Grzeschik et al. (36). Briefly, the PCR-amplified vNAR products from three non-immunized bamboo sharks were used as template for a consecutive threestep PCR. At first a cysteine in CDR1 was mutated to tyrosine to prevent the non-specific generation of disulfide bridges. In the second PCR, randomization of either $12,14,16$ or 18 amino acids in the CDR3 was performed using a codon-based trinucleotide mixture (EllaBiotech) that consisted of each amino acid-encoding trimer except the one for cysteine. Performing the third PCR allowed for attachment of homologous sequences for gap repair cloning in yeast with the linearized $\mathrm{pCT}$ vector (35). PCR products were purified using the Wizard ${ }^{\circledR}$ SV Gel and PCR Clean-up System (Promega) according to the manufacturer's protocol. The pCT plasmid used for gap repair cloning and surface presentation of vNAR variants was digested with the restriction enzymes NheI-HF and BamHI-HF and purified using the Wizard ${ }^{\circledR}$ SV Gel and PCR Clean-up System (Promega). Library generation in S. cerevisiae EBY100 cells was performed as described by Benatuil and colleagues (37). Each electroporation reaction consisted of $1.5 \mu \mathrm{g}$ digested pCT plasmid and $4.5 \mu \mathrm{g}$ insert. Altogether 10 transformation reactions per library were performed. Dilution plating was performed in order to determine the library size after three days.

\section{Yeast Library Screening}

Yeast cells were cultured as described (38). In short, transformed yeast cultures were incubated over night at $30^{\circ} \mathrm{C}$ in SD-CAA medium. Cells were collected via centrifugation, resuspended in SG-CAA medium at $\mathrm{OD}_{600}=0.7$ and cultivated overnight at $20^{\circ} \mathrm{C}$. For staining, cells were harvested and resuspended in BPBS (PBS $+0.1 \%$ BSA). In general, $10^{7}$ cells were incubated in a volume of $20 \mu \mathrm{l}$ and upscaled if necessary. For each staining a negative control in absence of target protein was included. For the first two sorting rounds cells were incubated with $1 \mu \mathrm{M}$ SUPB8 BCR and anti-c-myc-Biotin antibody (Miltenyi Biotec; 1:50 diluted) for $30 \mathrm{~min}$ on ice. After washing with BPBS, antigen binding was detected by application of anti-Human IgG Fc-PE conjugate (Affymetrix eBioscience; diluted 1:75) or Goat $\mathrm{F}\left(\mathrm{ab}^{\prime}\right) 2$ Anti-Human Lambda-PE (Southern Biotech; diluted 1:80) in combination with Streptavidin conjugated to APC or PE (Affymetrix eBioscience; diluted 1:75). Afterwards, cells were washed once with BPBS, resuspended in PBS and analyzed with a 
BD Influx ${ }^{\mathrm{TM}}$ cell sorter following the instructions of the manufacturer and analyzed via BD $\mathrm{FACS}^{\mathrm{TM}}$ Sortware v1.0. Setting of sort gates typically allowed $0.1 \%$ to $0.3 \%$ falsepositive cells as judged by control staining in the absence of antigen. After sorting cells were subsequently transferred to SDCAA medium for further incubation at $30^{\circ} \mathrm{C}$ for 2 days. Further sorting rounds were performed with at least a 10-fold excess of cells sorted out in the previous round to guarantee a sufficient coverage of the enriched populations. After enrichment of antigen-binding variants yeast cells plasmid DNA from antigen-binding populations was isolated using Zymoprep Yeast Plasmid Miniprep Kit (Zymo Research) and transformed into $\mathrm{DH} 5 \alpha$ competent $E$. coli cells. After incubation overnight plasmids were isolated and sent out for sequencing utilizing pCT_seq_lo and pCT_seq_up oligonucleotides.

\section{Expression of Selected vNAR-Fc Variants}

For expression of soluble vNAR molecules, genes were reformatted via fusion to human IgG1 Fc region encoded in the mammalian expression vector pEXPR-IBA42 (CosmoBio). For ligation NheI and ApaI sites and parts of the IgG1 hinge region were introduced via PCR. After restriction of entry plasmids and VNAR genes with the respective restriction enzymes and ligation and transformation of $E$. coli, sequencing of constructs was performed followed by transient transfection of Expi293F $\mathrm{F}^{\mathrm{TM}}$ cells using polyethyleneimine (Polysciences) according to the instructions of the manufacturer (Thermo Fisher Scientific). After 5 days, culture supernatants were harvested, sterile-filtered $(0.22 \mu \mathrm{m}$ Filtropur S 0.2, Sarstedt) and purified using Protein A spin columns. Buffer exchange was performed via dialysis against PBS using a membrane with a $\mathrm{MWCO} \sim 14 \mathrm{kDa}$.

\section{Binding Kinetics}

For evaluation of binding kinetics parameters measurements were carried out on Octet RED96 system (FortéBio) at $30^{\circ} \mathrm{C}$ and $1000 \mathrm{rpm}$ agitation in $200 \mu \mathrm{l}$. SUP-B8 BCR molecules were loaded on Anti-Human Fab-CH1 2nd Generation at $2 \mu \mathrm{g} / \mathrm{mL}$ in $\mathrm{KB}$ for $80 \mathrm{~s}$. After that tips were transferred to kinetics buffer (KB; PBS, $0.1 \%$ Tween 20 and 1\% BSA) for $60 \mathrm{~s}$ for sensor rinsing. Subsequently, association of varying concentrations from 2.4 to $200 \mathrm{nM}$ of different vNAR-Fc variants were measured for $300 \mathrm{~s}$ followed by dissociation for $300 \mathrm{~s}$ in KB. In each experiment, a negative control was performed by incubating the captured BCR molecules with unrelated antigen or incubating tips loaded with unrelated antigen with soluble vNAR-Fc. Data fitting and analysis was conducted with FortéBio data analysis software 9.1 with a 1:1 Langmuir binding model after Savitzky-Golay filtering.

\section{Cellular Binding}

Prior to analysis proteins were biotinylated using EZ-Link ${ }^{\mathrm{TM}}$ Sulfo-NHS-LC-Biotin (ThermoFisher) according to the instructions of the manufacturer. In scope of analyzing cellular binding, cells were sedimented and washed three times with $1 \%$ BPBS followed by incubation with the respective biotinylated vNAR-Fc constructs $(250,50$ or $10 \mathrm{nM}$ vNAR-Fc in $1 \%$ BPBS) for $1 \mathrm{~h}$. In the next step cells were washed and incubated with fluorescently labeled Streptavidin-APC (diluted 1:75) for $20 \mathrm{~min}$ and washed once again. In the end, cells were analyzed using a BD Influx flow cytometry device.

\section{Generation of vNAR Antibody-Drug Conjugates}

vNAR antibody-drug conjugates were generated upon enzymatic ligation of the antimitotic agent Monomethyl Auristatin E (MMAE) to the Fc fragment. Therefore, a genetically engineered $C$-terminal LPETGG extension was modified by an activity-optimized sortase variant (eSrtA) (39) from the Grampositive bacterial strain Staphylococcus aureus as described elsewhere (40). Briefly, vNAR-Fc molecules were incubated in the presence of 0.1 equivalents sortase $\mathrm{A}$ and 10 equivalents GGG-vc-PABA-PEG 3 -MMAE in reaction buffer $(150 \mathrm{mM} \mathrm{NaCl}$, $50 \mathrm{mM}$ TRIS, $10 \mathrm{mM} \mathrm{CaCl}_{2}$, pH 7.5 adjusted with $\mathrm{HCl}$ ) for $1 \mathrm{~h}$ at $22^{\circ} \mathrm{C}$. After protein modification, antibody-drug conjugates were purified via protein A chromatography (GE Healthcare), bufferexchanged and concentrated to required concentrations (Amicon ${ }^{\circledR}$ Ultra $15 \mathrm{~mL}$, Millipore).

\section{Cell-Based Assays}

\section{Isolation of Human Effector Cells}

Human macrophages were generated by an adherence method utilizing monocyte-attachment medium (PromoCell, Heidelberg, DE). After an incubation for $24 \mathrm{~h}$ in serum-free XVivo medium (Lonza, Basel, CH), M-CSF (PeproTech, Rocky Hill, CA, USA) was added for macrophage generation. Human MNC were isolated from peripheral blood of healthy volunteers, as previously described (41) using Ficoll ${ }^{\circledR}$ (GE Healthcare, Chicago USA).

\section{Chromium Release Assays}

ADCC was analyzed in [51Cr] release assays as described previously (41). Briefly, effector cells, antibodies and medium were added to round-bottom microtiter plates (Nunc, Rochester, NY, USA) and the assay was started by adding target cells. After $3 \mathrm{~h}$ at $37^{\circ} \mathrm{C},[51 \mathrm{Cr}]$ release from triplicate samples was measured. The percentage of cellular cytotoxicity was calculated using the formula: percentage of specific lysis $=($ experimental $\mathrm{cpm}-$ basal $\mathrm{cpm}) /($ maximal cpm - basal cpm $) \times 100$; maximal [51Cr] release was determined by adding $2 \% \mathrm{v} / \mathrm{v}$ Triton-X-100 to target cells, and basal release measured in the absence of sensitizing antibodies and effector cells.

\section{Phagocytosis Assays}

ADCP was analyzed by high-throughput microscopy using the IncuCyte $^{\circledR}$ (Sartorius, Göttingen, DE) system. Human macrophages served as effector cells in ADCP. For fluorescence staining, $1 \times 10^{6}$ target cells were labeled with $0.5 \mu \mathrm{g} / \mathrm{ml}$ pHrodo (ThermoFisher, Waltham, MA) for $1 \mathrm{~h}$ at room temperature. Afterwards, target cells were washed two times in PBS and diluted in either cell culture medium or $0.1 \mathrm{M}$ glycine $\mathrm{pH} 3$ as positive control. The effector cell to target cell ratio (E:T ratio) was $1: 1$ with $0.4 \times 10^{5}$ target cells as well as macrophages being seeded per well. After adding antibodies at various 
concentrations, ADCP was measured for $12 \mathrm{~h}$ at an interval of 30 min and analyzed using IncuCyte ${ }^{\circledR}$ software tools.

\section{Internalization Assays}

vNAR-Fc fusion proteins were conjugated with $\mathrm{pHAb}$ amine reactive dye according to manufacturer's recommended protocol (Promega). Briefly, antibodies were reacted at lysine amino acids with a 20 molar excess of amine reactive pHAb dye for $1 \mathrm{~h}$. Unbound dye was subsequently removed using a Zeba desalting column (Thermo-Scientific). For internalization, B cells were plated at the density of $2 \times 10^{4}$ vial cells per well and treated overnight with pHAb conjugated vNAR-Fc antibodies at desired concentrations. Plates were read on a fluorescent plate reader at Ex/Em: $532 \mathrm{~nm} / 560 \mathrm{~nm}$.

\section{Cell Proliferation Assays}

Cytotoxic effect of vNAR constructs was evaluated by exposing on-target SUP-B8 lymphoma B-cells or off-target cells to different antibody concentrations. Cell viability was analyzed $72 \mathrm{~h}$ after addition of vNAR-Fc variants with the CellTiter $96^{\circledR}$ AQueous One Solution Cell Proliferation Assay (Promega). Briefly, $1 \times 10^{4}$ cells were seeded per well in a 96-well plate in $90 \mu \mathrm{l}$ RPMI 1640 medium and treated with $10 \mu \mathrm{l}$ vNAR-Fc antibody to reach final concentrations of $\sim 20 \mathrm{pM}$ up to $1 \mu \mathrm{M}$. After $72 \mathrm{~h}, 20 \mu \mathrm{l}$ of the MTS solution were added per well and the plates were incubated for $2 \mathrm{~h}$ under standard conditions. Finally, the absorption of each well was measured at $490 \mathrm{~nm}$ in a Tecan reader. Cell proliferation in reference wells with untreated cells was set to $100 \%$.

\section{Statistical Analysis}

Statistical analysis was conducted using SigmaPlot 12.5 (Systat Software, Inc.). Data are presented as mean \pm standard error of the mean (SEM) of at least three independent experiments. Statistical significance was determined using a two-way ANOVA test (Bonferroni t-test). $p$ values $<0.05$ were considered to be statistically significant.

\section{RESULTS}

\section{Identification and Generation of Lymphoma Cell-Specific B-Cell Receptors}

In order to identify lymphoma BCRs and provide them in soluble form for library screening to obtain anti-idiotypic shark-derived antibodies, three different lymphoma cell lines, namely Daudi, IM-9, and SUP-B8 were used. First step was the generation of cell-specific soluble BCR molecules for their later use as antigen in a FACS-based selection process. Therefore, all cell lines were cultured, followed by RNA extraction and subsequent cDNA synthesis using random hexamer primers. Afterwards, the synthesized cDNA served as template for amplification of $\mathrm{V}_{\mathrm{H}}$ and $V_{L}$ genes using primers reported in a study by Maleshko et al. (34) that elucidated a specially designed panel of primers for the rapid amplification of variable regions of tumor immunoglobulins (Tab. S1). The primers enabled the specific amplification of four possible immunoglobulin chain types IgM, IgG, IgK, and IgL. After amplification of $\mathrm{V}_{\mathrm{H}}$ and $\mathrm{V}_{\mathrm{L}}$ domains showing the correct fragment size (Figure S1A), purified PCR products were sent for sequencing. Resulting sequences were aligned to the published sequences of all three BCR variants (42, 43) and can be found in Figure S2. To use the 3 BCRs as antigen in FACS based screening process in the next steps, the variable domains were cloned on the Fc-scaffold of matuzumab (44). For heavy chains, $\mathrm{V}_{\mathrm{H}}$ domains of matuzumab were exchanged against the identified $\mathrm{BCR} \mathrm{V}_{\mathrm{H}}$ domains. Due to the lack of correct restriction sites for light chains, $V_{L}$ of Daudi and IM-9 were fused via PCR to $C_{\text {Kappa }}$ domains and $V_{L}$ of SUP-B8 to $\mathrm{C}_{\text {Lambda, }}$, respectively (Figure S1A).

After sequence verification, all constructs were cloned into pTT5 vectors for expression in HEK $293 \mathrm{~F}$ cells as described elsewhere (45). Five days after transient transfection, cell cultures were harvested and supernatants were purified using Protein-A spin columns followed by dialysis against PBS. Analysis using SDS-PAGE revealed the presence of all three BCR variants after purification (Figure S1B). The BCRs of SUP-B8 and IM-9 showed the correct band pattern with heavy and light chain bearing the correct size. However, the BCR variant of the Daudi cell line showed a smearing band corresponding to the light chain with a higher apparent molecular size than predicted. We did not further investigate whether this difference in molecular weight is due to Daudi $\mathrm{V}_{\mathrm{L}}$ domain glycosylation.

\section{Yeast Library Screening}

To investigate whether specific anti-idiotypic vNARs can be obtained, the BCR of cell line SUP-B8 was utilized as antigen in a FACS-based screening process using the semi-synthetic vNAR yeast surface display library with randomized CDR3 loops in different lengths of 12 to 18 amino acids (32). Consequently, the libraries were screened by FACS for binders of recombinant SUP-B8 BCR protein. Target binding was identified by indirect antigen fluorescence staining. vNAR surface display level was analyzed simultaneously by labeling of the $C$-terminally located c-Myc tag. Negative controls in absence of antigen were carried out to evaluate the enrichment of binders directed against the staining reagents considered in the gate strategy. As depicted in Figure 2, we were able to enrich a SUPB8 BCR-positive yeast population within three consecutive screening rounds by employing $1 \mu \mathrm{M}$ antigen. Moreover, no significant binding against secondary detection reagents was observed.

Polyclonal anti-human IgG Fc-PE conjugate served as detection reagent in each round. However, to prevent the isolation of vNAR variants directed against this reagent, the third sorting round was repeated using anti-human Lambda-PE, recognizing the $\mathrm{C}_{\text {Lambda }}$ domain of SUP-B8 BCR (Figure S3). To assess the specificity of the enriched binding populations, target binding to IM-9 BCR and Cetuximab was analyzed and revealed no significant binding (Figure S4).

A total of 15 yeast clones were selected and analyzed for their target-specific binding to the SUP-B8 BCR using flow cytometry (Figure S5). This resulted in 13 clones showing surface presentation and specific BCR binding. Afterwards, sequencing 


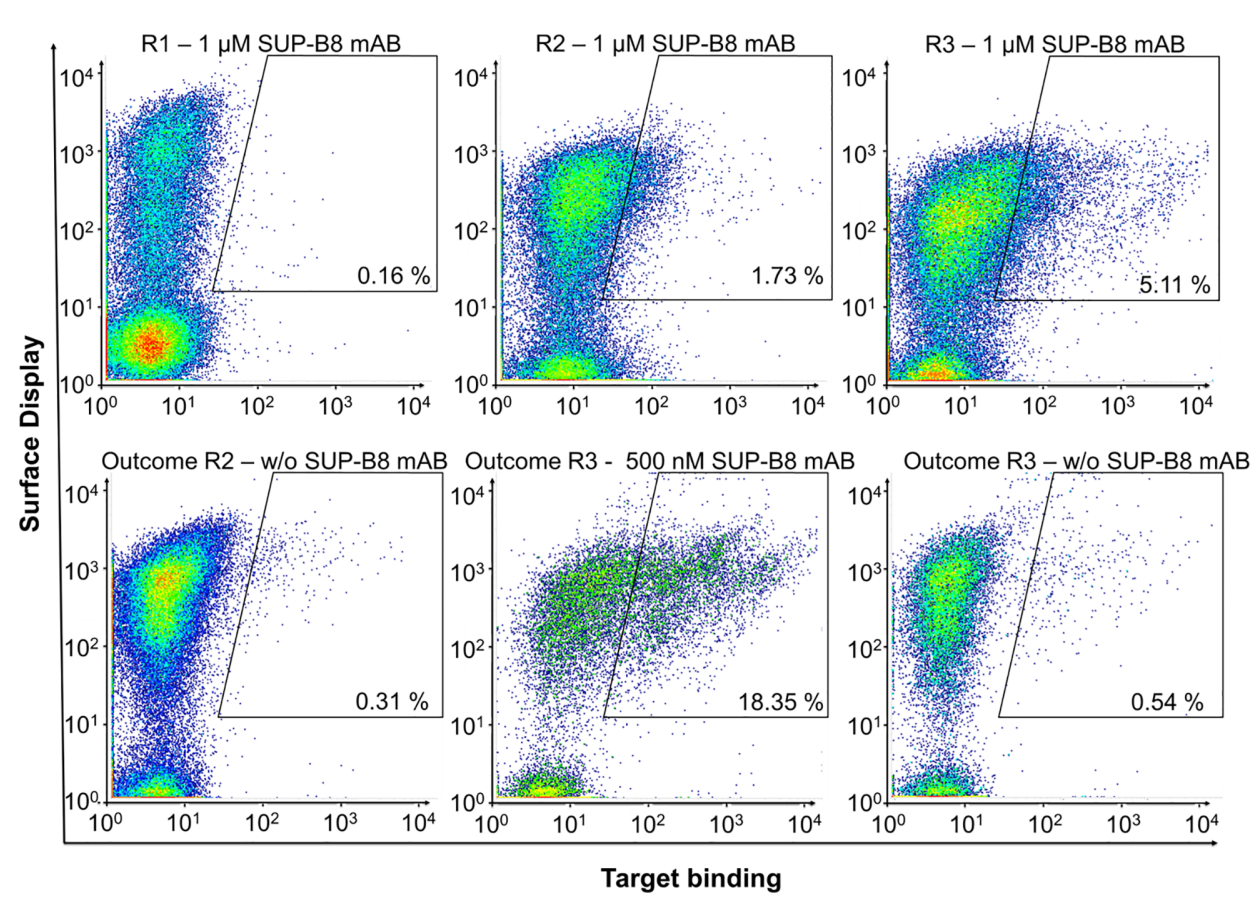

FIGURE 2 | Shark-derived VNAR library screening against the BCR of cell line SUP-B8. Sorting gates, percentages of cells in the respective gate and target concentrations are shown. Anti-Human FC-PE served as detection reagent. $1 \mathrm{~d}$ after induction, yeast cells were labeled for parallel detection of antigen-binding and surface presentation. In each round, cells in the sorting gate of the upper plots were isolated, grown and induced for the next round of selection. Outcome selected rounds of screening were analyzed for specific enrichment (lower plots).

was performed to evaluate the CDR3 loop sequences and to determine the clone diversity still present in this populations.

Sequencing revealed the presence of 11 unique single clones showing different CDR3 loop lengths of 12 to 16 amino acids (Figure 3). No variant comprised of 18 amino acids in CDR3 was enriched in the screening process.

\section{Generation and Characterization of vNAR- Fc Variants}

For further characterization of the identified variants, eight clones in total were chosen for reformatting based on reliable sequence patterns and expressed as vNAR-Fc fusion proteins in HEK $293 \mathrm{~F}$ cells. After production and purification via protein A affinity chromatography, the proteins were assessed by SDSPAGE, indicating for five clones bands with the expected molecular weight of approximately $40 \mathrm{kDa}$ as well as a high purity (Figure S6). For characterization, binding kinetics of binders resulting from screening campaigns were determined via biolayer interferometry (BLI). This resulted for four clones in binding affinities ranging from low single-digit nanomolar to low double-digit nanomolar binding constants (Figure S7).

To assess the specificity of soluble vNAR-Fc variants, binding to the BCRs of the unrelated cell line IM-9 was investigated. This resulted in three variants $\mathrm{S} 2, \mathrm{~S} 4$, and S9 that revealed mainly specific binding whilst one variant (S7) showed significant binding intensity to the unrelated BCR of cell line IM-9 (Figure S8). Within this study we aimed to demonstrate the feasibility of shark-derived vNAR antibody fragments selected via yeast surface display for specific targeting of lymphoma cells. Cellular binding to SUP-B8 cells was therefore analyzed to prove the binding not only to the recombinantly expressed BCRs used as antigen for screening procedure but also to the native surfacepresented BCR. Prior to analysis of cellular binding, surface expression of BCRs was verified by staining cells with antihuman lambda-PE or anti-human kappa-PE (Figure S9). Selective cellular binding was analyzed by comparing the binding to SUP-B8 cells with unspecific binding to BCRpresenting Daudi and IM-9 cells. Binding experiments indicated for 2 variants S2 and S9 a highly specific cellular binding in an idiotypic manner (Figure 4A). Moreover, experiments including primary $\mathrm{B}$ cells isolated from healthy donors demonstrated the capability of the VNAR-Fc fusion proteins to discriminate between the idiotype of the malignant clone and a plethora of idiotypes expressed by healthy B cells of an individual (Figure 4B). Of note, higher cell surface BCR expression levels were observed on lymphoma B cells compared with healthy B cells (Figure S10). Next, the ability of the vNARbased antibodies to cluster the idiotype of the lymphoma B cells triggering BCR signal transduction was investigated. Antibody treatment of lymphoma cell lines showed stimulation of intracellular Syk phosphorylation, revealing specific mediation of BCR signaling (Figure 4C).

Given the final goal of specific opsonizing lymphoma B cells, the impact on receptor-mediated endocytosis was also 


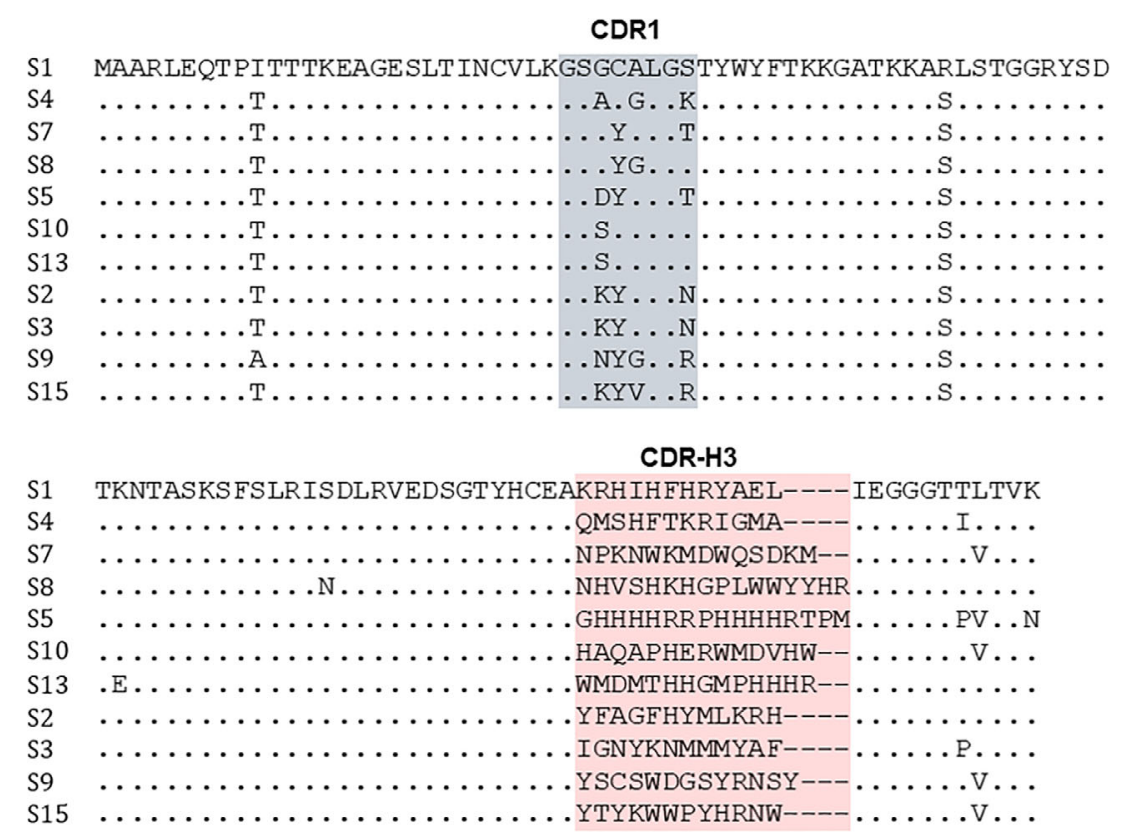

FIGURE 3 | Sequence alignment of VNAR-Fc variants binding the BCR of lymphoma cell line SUP-B8. Sequencing was performed with clones derived from population after three rounds of FACS screening using yeast display. CDR1 and CDR3 binding sites are depicted in grey and red.

investigated. vNAR-Fc antibodies revealed high internalization levels upon specific engagement of the BCR (Figure S11).

\section{vNAR-Mediated Tumor Cell Killing}

Previous publications have shown the potential of BCR-binding peptibodies bearing four binding valences to kill tumor cells in vitro specifically by inducing cell apoptosis upon clustering of surface BCRs (23). Initial experiments utilizing both vNAR-Fc variants bearing only two binding valences showed no significant cell killing effect on SUP-B8 cells (Figure S12A). Likewise, a tetravalent version with four vNARs fused to the hinge region mediated no cell killing. To analyze whether the novel molecules trigger Fc-mediated effector functions, the capability of the vNAR-Fc molecules to specifically mediate ADCC and ADCP against malignant $\mathrm{B}$-cells was investigated in ${ }^{51}$ chromium release assays using increasing antibody concentrations and PBMCs or macrophages, respectively, as effector cells (Figure S13). For unknown reasons, no antibody-dependent cell-mediated cytotoxicity or antibody-dependent cellular phagocytosis was observed in these assays.

As an alternative approach, we intended to generate antibody-drug conjugates for specific induction of cell killing in SUP-B8 lymphoma B-cells. Therefore, sortase A-mediated modification of our two most promising vNAR candidates S2 and S9 with monomethyl auristatin E (MMAE) was carried out (Figure 5A).

To this end, on-target SUP-B8 cells as well as off-target Daudi and IM-9 cells were treated with MMAE-conjugated vNAR-Fc constructs at concentrations ranging from $\sim 20 \mathrm{pM}$ to $1 \mu \mathrm{M}$. S2 and S9 antibody-drug conjugates mediated specific cytotoxicity in target SUP-B8 cells with $\mathrm{IC}_{50}$ values in picomolar range (517 $\mathrm{nM}$ and $136 \mathrm{nM}$, respectively) and similar maximal level of lymphoma cell lysis (Figures 5B, C). A cytotoxic effect was observed in off-target Daudi and IM-9 cells at higher antibody concentrations, showing, however, up to 345-fold higher $\mathrm{EC}_{50}$ values. Induction of specific cell death was additionally confirmed in an Annexin V FACS assay (Figure 5F). Of note, no significant killing effect could be detected on unrelated $\mathrm{CHO}$ cells (Figure S12B). Cell death induced in off-target cell lines might not be vNAR-related, as shown in experiments including isotype controls as well as vNAR-devoid Fc-MMAE molecules (Figures 5D, E). Differences observed between cell lines might be derived from varying overall sensitivity to the drug.

\section{DISCUSSION}

Using anti-idiotypic antibodies to target lymphoma B-cells has aroused interest in the scientific community a long time ago. The BCR might represent an ideal tumor-specific marker since this functionally active molecule is unique for each B-cell clonal population. Indeed, anti-idiotype antibody therapy in lymphoma patients has been shown to be successful in small clinical studies (46). The consequent need of developing a custom-tailored therapy, however, delayed further progress.

In this study we demonstrate the suitability of semisynthetic shark-derived vNAR antibodies for the development of a cost and time-effective personalized therapy against B-cell lymphoma. Thus, a yeast-displayed CDR3-randomized vNAR library generated from non-immunized bamboo sharks was 
A
SUP-B8 + vNAR-Fc S2

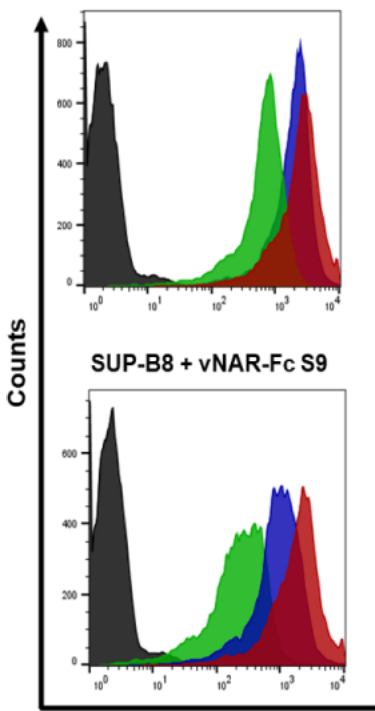

- Negative control
Daudi + vNAR-Fc S2

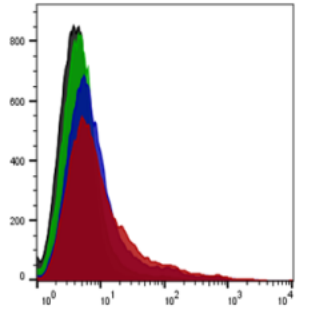

Daudi + vNAR-Fc S9

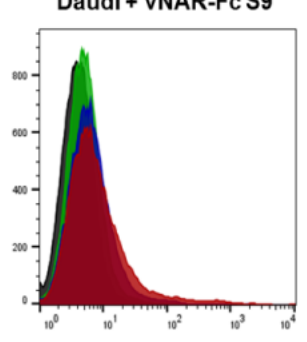

Cellular binding
IM-9 + vNAR-Fc S2

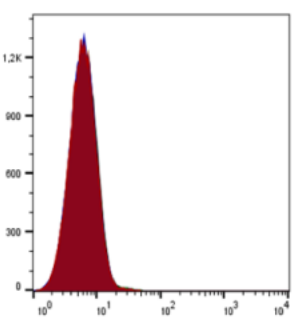

IM-9 + vNAR-Fc S9

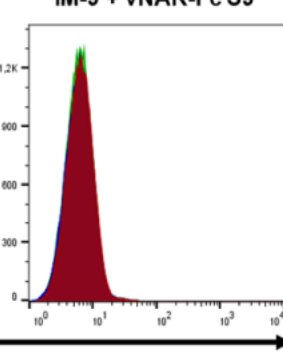

$250 \mathrm{nM}$

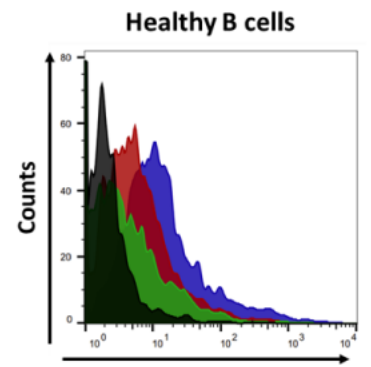

Cellular binding

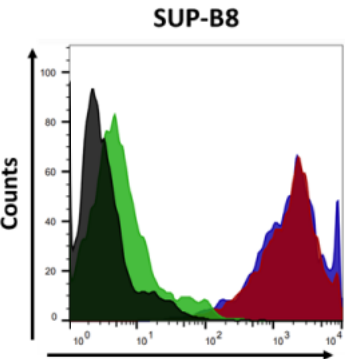

Cellular binding

- Negative control Unrelated vNAR $\square$ vNAR-Fc (S2) घvNAR-Fc (S9)

\section{C}

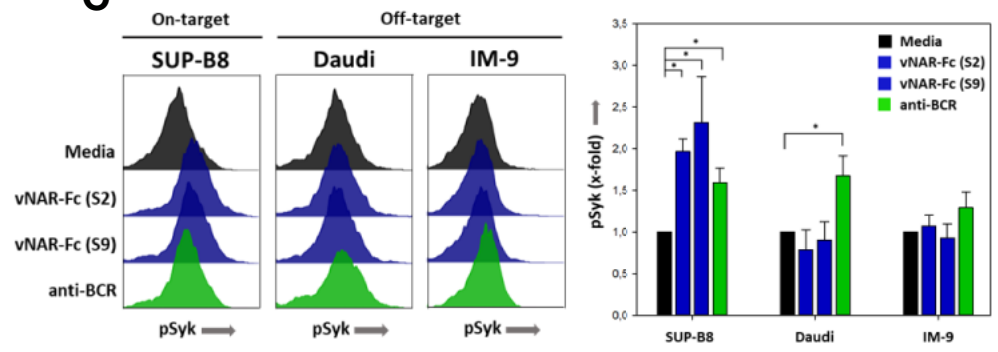

FIGURE 4 | Specific cellular binding of VNARs to cell line SUP-B8. Two generated vNAR-Fc variants were analyzed for their binding to the B-cell lymphoma cell lines SUP-B8, Daudi and IM-9 by flow cytometry. $2 \times$ $10^{5}$ cells were incubated with biotinylated vNAR-Fc molecules followed by incubation with streptavidin-APC. Black: only secondary reagent; red: 250 nM vNAR-Fc; blue: 50 nM vNAR-Fc; green: 10 nM vNAR-Fc (A). CFSE-labeled SUP-B8 cells were mixed with B cells (ratio 1:1) isolated from healthy donors and treated with a saturating 100-nM concentration of biotinylated VNAR-FC antibodies followed by staining with

streptavidin-APC. Black: only secondary reagent; green: unrelated anti-matuzumab vNAR-Fc; blue: vNAR-Fc (S2); red: vNAR-Fc (S9) (B). Lymphoma B cells were incubated with vNAR-Fc antibodies at a saturating 100-nM concentration. After incubation for $5 \mathrm{~min}$ at $37^{\circ} \mathrm{C}$, cells were fixed with paraformaldehyde followed by permeabilization with ice-cold methanol. Intracellular Syk phosphorylation was detected upon staining with an anti-phospho Syk antibody (Cell Signaling Technology). Significant differences $(p \leq 0.05)$ between antibody and control treatment were determined using a one-way ANOVA test (Holm-Sidak test) and are

depicted by * (C). Results are shown as mean \pm SD and are representative of three independent experiments. 
Macarrón Palacios et al.

Specific Targeting of Lymphoma Cells

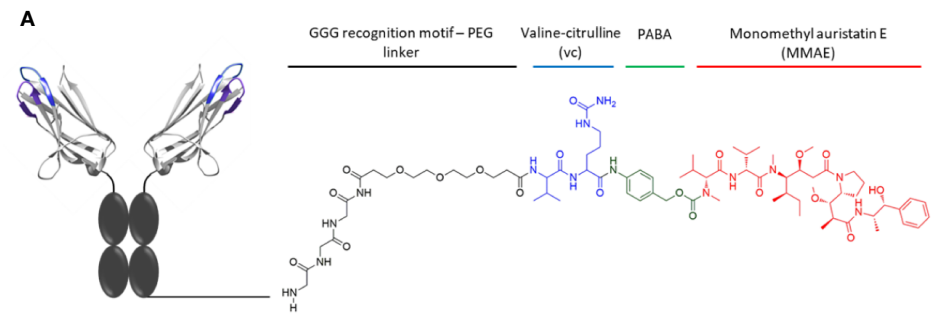

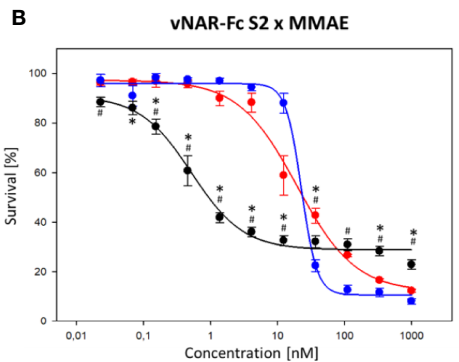

- SUP-B8 $\mathrm{EC}_{50}=0.52 \pm 0.11 \mathrm{nM}$; Max. lysis $=77.1 \%$ $\begin{array}{ll}\text { Saudi } & \mathrm{EC}_{50}=19.48 \pm 2.83 \mathrm{nM} \text { (38-fold) } \\ \mathrm{IM}-9 & \mathrm{EC}_{50}=22.68 \pm 1.3 \mathrm{nM} \text { (44-fold) }\end{array}$

D

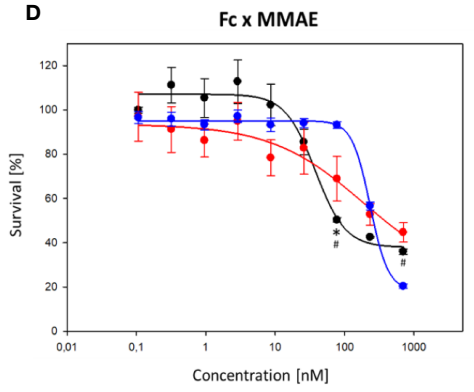

- SUP-B8 $\mathrm{EC}_{50}=37.79 \pm 7.77 \mathrm{nM}$; Max. lysis $=64.07 \%$

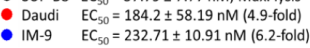

C

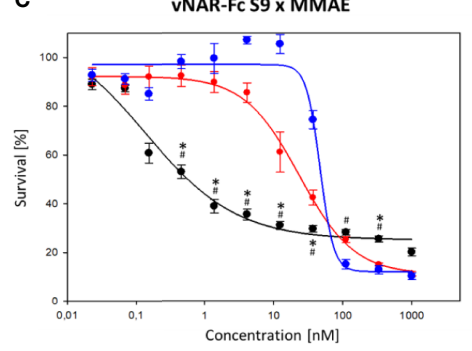

- SUP-B8 $\mathrm{EC}_{50}=0.14 \pm 0.08 \mathrm{nM}$; Max lysis $=79.9 \%$ - audi $\mathrm{EC}_{50}=23.37 \pm 4.13 \mathrm{nM}(172$-fold $)$

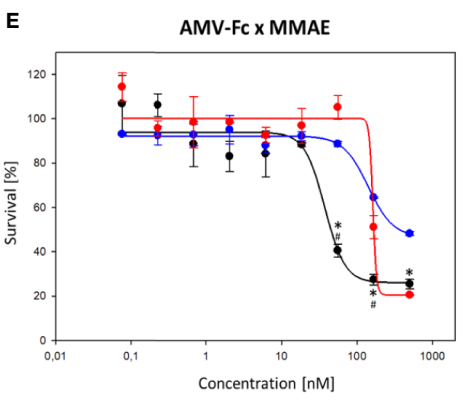

- SUP-B8 $\mathrm{EC}_{50}=37.45 \pm 9.51 \mathrm{nM}$; Max lysis $=74.5 \%$ $\begin{array}{ll}\text { - Daudi } & \mathrm{EC}_{50}=140.82 \pm 18.92 \mathrm{nM}(3.8 \text {-fold }) \\ \text { - IM-9 } & \mathrm{EC}_{50}=162.44 \pm 42.34 \mathrm{nM} \text { (4.3-fold) }\end{array}$

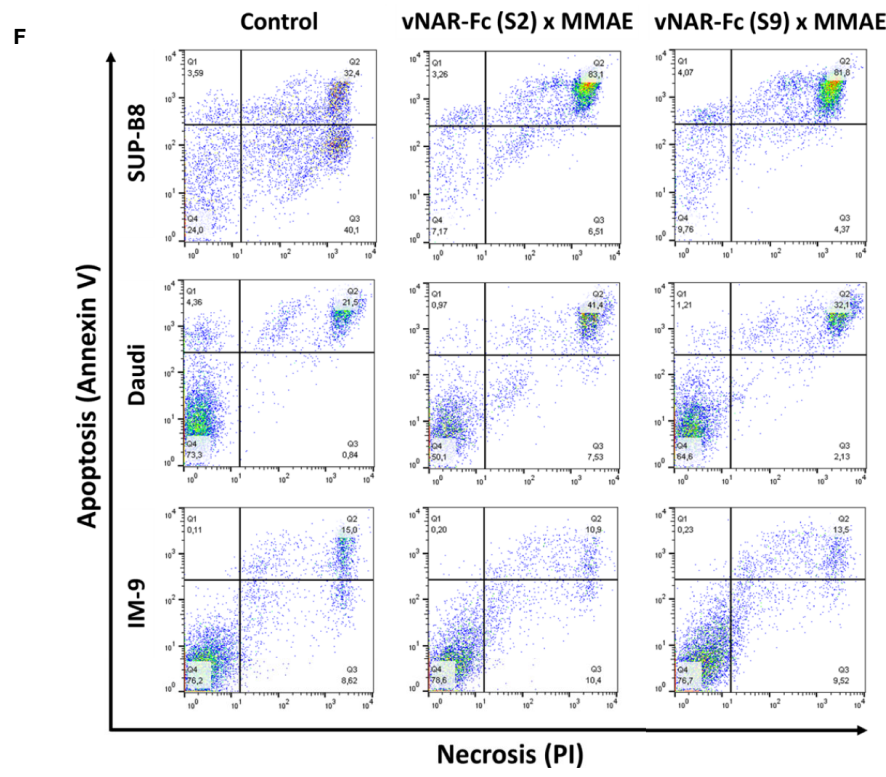

FIGURE 5 | Continued

Frontiers in Immunology | www.frontiersin.org

10

November 2020 | Volume 11 | Article 560244 
FIGURE 5 | Induction of cytotoxicity in SUP-B8 cells by vNAR-based antibody-drug conjugates. A genetically engineered Fc fragment was MMAE-modified by using a sortase to generate vNAR-based antibody-drug conjugates. PABA: $p$-aminobenzoic acid (A). On-target SUP-B8 as well as off-target Daudi and IM-9 wells were exposed to varying concentrations of two different MMAE-conjugated vNAR-FC antibodies (B, C). FC-mediated cytotoxicity was assessed upon cell treatment with MMAE-modified solitary FC fragment (D) and unrelated MMAE-conjugated anti-matuzumab vNAR-Fc (isotype control) (E). vNAR-mediated cytotoxicity was measured based of cell proliferation after $72 \mathrm{~h}$ of antibody treatment. Results are shown as mean \pm SEM and are representative of three independent experiments. Significant differences $(p \leq$ 0.05) between on-target and control Daudi and IM-9 cells were determined using a two-way ANOVA test (Bonferroni t-test) and are depicted by * and \#, respectively. Mediation of apoptosis and necrosis was investigated upon treatment of $3 \times 10^{5}$ cells with a 500-nM concentration of vNAR-ADCs. After $24 \mathrm{~h}$ of incubation, cells were stained with Annexin $\vee$ and propidium iodide (PI) following manufacturer's protocol (Rottitest $\circledast$ Annexin $V$, Carl Roth) and analyzed by FACS (F).

used. First, immunoglobulin variable fragments of lymphoma cell lines were cloned, followed by reformatting and subsequent expression of recombinant idiotype proteins. A possible alternative to this procedure would have been the generation of hybridoma cell lines enabling the secretion of soluble BCR (24) which would have been a far more time-consuming process.

Furthermore, sequence analysis revealed for BCRs of cell lines Daudi and IM-9 comprising a kappa light chain whereas cell line SUP-B8 showed the sequence pattern of a lambda light chain. Consequently, the $\mathrm{V}_{\mathrm{L}}$ domains were cloned on the respective constant domains to prevent the generation of molecules lacking stability (47). Cloning into expression vectors enabled the production as full-length IgG bearing an IgG1 Fc and the subsequent purification via protein A columns. BCRs of SUPB8 and IM-9 showed the expected band patterns with heavy and light chains with correct sizes. However, analyzing Daudi BCRs revealed a light chain with a smearing band corresponding to the light chain with a higher apparent molecular size than expected. This might be caused by the presence of two motifs (N-X-S/T) for glycosylation sites in the CDR loops of Daudi $V_{L}$ (48). In general, BCR CDR loops frequently acquire sequence motifs upon somatic mutation that serve as sites for $\mathrm{N}$-glycosylation e.g. in follicular lymphoma (49).

Previous studies have shown the potential of vNARs to interact with the paratope of monoclonal antibodies in an antiidiotypic manner (33). This might be caused by anti-idiotypic vNARs being structurally capable of engaging interspaces at the interaction site of heavy and light chains of a monoclonal antibody, which could be attributed to their elongated CDR3 binding sites (27). After FACS-based yeast surface display screening of the semi-synthetic vNAR-library, the resulting population of binders still showed a high diversity which enabled to select the most promising variants. Although no counter-screen using unrelated antibodies was implemented, it could be shown that the majority of binders specifically recognize the antigen in an idiotypic manner. Furthermore, it has to be mentioned that all binders resulting from this study mainly bind via amino acid residues in the CDR3. Eight vNAR variants were reformatted via fusion to a human Fc. Of these, five were able to be expressed at reasonable yields $(50-100 \mathrm{mg} / \mathrm{L})$. Depending on CDR sequences, it is a well-known problem of many single-chain antibodies to show low expression yields $(50,51)$. Evaluation of vNAR affinities was performed by application of biolayer interferometry revealing binding constants in the single-digit nanomolar range. Specificity was assessed again with soluble protein which resulted for three variants (S2, S4 and S9) in highly specific binding to the BCR of cell line SUP-B8. This was also true for binding to BCR presenting SUP-B8 cells clearly showing a specific cellular binding. This also indicated the recombinantly expressed BCR being folded similarly as the wildtype membraneanchored BCR. The combinatorial diversity of the naïve antibody repertoire in humans is estimated to be at least $10^{12}$ unique BCRs (52). The immense plethora of different idiotypes within an individual could diminish binding thus limiting the effectiveness of the antibodies. In this study, vNAR-Fc fusion proteins were ultimately demonstrated to specifically engage the idiotype of a malignant cell population being able to distinguish from BCRs expressed by healthy B cells.

Receptor-mediated endocytosis plays an important role in cell death induction. BCR clustering and thus triggering of cell apoptosis might be impaired by rapid antibody internalization, while efficacy of antibody-drug conjugates is to a large extent driven by receptor-mediated antibody endocytosis followed by release of the toxic compound finally causing cell death (53). Treatment of lymphoma B cells with vNAR-Fc fusion molecules revealed BCR signal transduction as well as extensive internalization upon binding of the specific BCR. As expected, control lymphoma cell lines Daudi and IM-9 bearing different idiotypes showed significantly lower antibody internalization levels, likely due to $\mathrm{Fc} / \mathrm{Fc} \gamma$ receptor interactions rather than upon unspecific vNAR-mediated BCR engagement. Torchia et al. have reported anti-idiotype peptibodies bearing four binding valences to kill lymphoma cells in vitro with specificity via induction of cell apoptosis by clustering the surface BCRs (23). Consequently, we investigated our most promising vNARFc variants S2 and S9 towards their potential cell killing effect on SUP-B8 cells. This resulted in no observable cytotoxicity even at higher triple-digit nanomolar concentrations. The lack of vNARFc-triggered BCR clustering is concordant with different reports describing that constructs with only two binding valences show significantly reduced receptor clustering (54). Moreover, neither addition of an anti-human Fc antibody to SUP-B8-bound vNAR-Fc nor application of a tetravalent construct with two additional $C$-terminally fused vNAR domains lead to a significant induction of apoptosis (data not shown). It is tempting to speculate that these observations are mainly reasoned through rapid internalization and degradation of vNAR-Fc/BCR complexes triggered by either BCR crosslinking or interaction of $\mathrm{FC}$ region of vNAR constructs with the Fc $\gamma$ receptors expressed on lymphoma B-cells (55). Upcoming studies may reveal whether this issue can be circumvented by cloning the genes coding for BCR-binding vNARs into higher multivalent antibody formats. In the case of VHHs, Drabak et al. reported that it is feasible to generate 
tetravalent $\mathrm{VHH}-\mathrm{Fc}$ molecules either consisting of two $\mathrm{VHH}$ domains $\mathrm{N}$-terminally fused to the constant domain or located at both termini of the Fc portion (56). Furthermore, it would be possible to use one of the several published scaffolds that enable multivalent conjugation of proteins e.g. verotoxin B $(57,58)$ or the C4-binding protein (59). Previous studies have shown that B cell activation is triggered by BCR-antigen engagement (60). Forthcoming studies might reveal more details regarding BCR activation and eventually internalization upon engagement of anti-idiotypic antibodies.

Next, we investigated the potential of the vNAR-Fc molecules to specifically mediate ADCC and ADCP against lymphoma Bcells. Unexpectedly, experiments revealed no activity to activate human PBMCs and macrophages for ADCC/ADCP. It is known that Fc glycosylation plays a critical role in binding to human $\mathrm{FC}$ receptors and consequently in triggering ADCC or ADCP. Improper glycosylation patterns present on the vNAR-Fc antibodies might explain the inefficacy of the Fc fragment to induce antibody-mediated cytotoxicity/phagocytosis against malignant B-cells. In addition, a variety of target antigen characteristics, such as epitope location, antigen density or molecule design have been described to critically impact Fcmediated effector functions. We did not further investigate these parameters within the scope of this work.

Besides triggering apoptosis by BCR clustering and engagement of effector cells, it is feasible to investigate the killing effect of an antibody-drug conjugate. Here, we report a patient-tailored approach in a proof of concept study based on the generation of vNAR antibody-drug conjugates that kill lymphoma B-cells upon specific vNAR-mediated targeting of the BCR. Enzymatic MMAE-modification of the SUP-B8 BCRbinding vNAR-Fc candidates S2 and S9 resulted in specific induction of cytotoxicity in on-target lymphoma B cells at picomolar concentrations. In contrast, the vNAR-ADCs showed no significant cytotoxic effect in unrelated $\mathrm{CHO}$ cells as well as off-target $\mathrm{B}$ cells in the same picomolar range. Of note, increasing ADC concentrations led to killing of off-target lymphoma B cells. Nonspecific cell death caused by lymphoma B-cell targeting antibody-drug conjugates has been observed in similar studies (61). As discussed before, this effect might be derived from antibody/antigen complex uptake and internalization via interaction with $\mathrm{Fc} \gamma$ receptors present on B cells. Experiments including vNAR-unrelated constructs as isotype control as well as solitary MMAE-modified Fc molecules support our hypothesis of $\mathrm{Fc} / \mathrm{Fc} \gamma$ receptor interactions being responsible for unspecific cell killing induced in off-target Daudi and IM-9 cells. Furthermore, similar cell surface BCR expression levels were observed for all three lymphoma cell lines. Interestingly, we noticed that SUP-B8 cells respond more sensitive to both isotype control and MMAE-conjugated Fc domain. This might be explained by a higher surface Fc $\gamma$ receptor density compared to Daudi and IM-9 cells, by an increased antibody/receptor complex internalization rate or by a different intracellular processing after antibody-toxin uptake. Despite inducing a nonspecific cytotoxic effect, the Fc region is responsible for improved stability and pharmacokinetics and may promote cell apoptosis by BCR clustering in toxin-free multivalent antibody formats.

ADCs for treatment of B-cell non-Hodgkin's lymphoma and follicular or diffuse large B-cell lymphoma developed by Genentech/Roche are being investigated in actual Phase I and Phase II clinical trials (11). Currently, patients with B-cell lymphomas such as Burkitt lymphoma and several other NonHodgkin lymphoma types are treated with a combination of extensive chemotherapy with Rituximab that binds selectively the B-lymphocyte antigen CD20. Although this therapy has shown to be very effective, especially utilizing Rituximab for treatment has several potential disadvantages. On the one hand Rituximab opsonizes all cells that express the tumor-associated antigen CD20. The resulting suppression of the whole immune system increases the risk of infections and viral reactivation (12). On the other hand it also removes a large population of antigenpresenting cells (APCs) important for initiation of T-cellmediated cellular immunity (62). Further risks are associated with loss of CD20 expression or the development of lymphoma cells showing mutated CD20 protein on their surface. As a consequence, cancer cells are not able anymore to be targeted by Rituximab $(63,64)$. Thus, incomplete depletion of malignant $\mathrm{B}$ cells often results in disease relapse and treatment resistance in patients (65).

Due to their remarkably attributes, harnessing heavy-chain only antibodies from the adaptive immune system of cartilaginous fish seems to be a promising approach for the development of novel therapeutic molecules. Given the substantial evolutionary distance of cartilaginous fish to human, however, potential immunogenicity should be taken into consideration. Yet, previous studies have demonstrated the feasibility of humanizing vNAR domains in order to prevent xeno-reactivity (66).

In summary, considering the BCR as tumor-specific cell surface marker which is also distinct from the BCRs displayed on non-malignant B cells, we developed a novel strategy for a custom-tailored targeted therapy to induce death in lymphoma B cells in a time efficient and inexpensive manner. The herein demonstrated versatile approach enables the generation of vNAR antibody drug conjugates against patient-specific lymphoma cells in a time of less than six months from time point of starting with material of lymphoma patients. The high specificity of our vNAR antibodies offers a therapeutic window enabling the eradication of lymphoma B cells without inducing overall immunosuppression derived from the ablation of the whole B-cell subset in patients. Future experiments may enable the generation of vNAR-Fc antibody formats with higher binding valences that allow for apoptosis induction of lymphoma B cells by BCR clustering.

\section{CONCLUDING REMARKS}

Several therapies based on monoclonal antibodies as well as small molecules against malignant B cells have been developed 
during the last years. These treatments, however, target B cells in a non-specific manner, thus leading to immunosuppression and finally to severe side effects (12). The use of antibody-drug conjugates based on anti-idiotypic vNARs specifically targeting the BCR might represent a beneficial strategy to induce killing in lymphoma B cells. The versatile approach described here as an in vitro proof of concept may overcome technical hurdles derived from the development of a patient-tailored treatment against lymphoma-related malignancies.

\section{DATA AVAILABILITY STATEMENT}

The original contributions presented in the study are included in the article/Supplementary Material. Further inquiries can be directed to the corresponding author.

\section{ETHICS STATEMENT}

The studies involving human blood donors were reviewed and approved by the ethics committee of the medical faculty of the Christian-Albrechts-Universität zu Kiel (Arnold-Heller-Str: 3;24105 Kiel).

\section{AUTHOR CONTRIBUTIONS}

AM, JG, and HK conceived and designed the experiments. AM, JG, LD, TR, and MP performed the experiments. AM, JG, TR, $\mathrm{MP}$, and HK analyzed the data. SK and SZ gave scientific advice.

\section{REFERENCES}

1. Ecker DM, Jones SD, Levine HL. The therapeutic monoclonal antibody market. MAbs. MAbs (2015) 7(1):9-14. doi: 10.4161/19420862.2015.989042

2. Kaplon H, Reichert JM. Antibodies to watch in 2018. MAbs (2018) 10(2):183203. doi: 10.1080/19420862.2018.1415671

3. Oldham RK, Dillman RO. Monoclonal antibodies in cancer therapy: 25 years of progress. J Clin Oncol (2008) 26:1774-77. doi: 10.1200/JCO.2007.15.7438

4. Armitage JO, Weisenburger DD. New approach to classifying non-Hodgkin's lymphomas: clinical features of the major histologic subtypes. Non-Hodgkin's Lymphoma Classification Project. J Clin Oncol (1998) 16:2780-95. doi: 10.1200/JCO.1998.16.8.2780

5. Swerdlow SH, Campo E, Pileri SA, Harris NL, Stein H, Siebert R, et al. The 2016 revision of the World Health Organization (WHO) classification of lymphoid neoplasms. Blood (2016) 127(20):blood-2016-01-643569. doi: 10.1182/blood-2016-01-643569

6. Carnahan J, Wang P, Kendall R, Chen C, Hu S, Boone T, et al. Epratuzumab, a humanized monoclonal antibody targeting CD22: characterization of in vitro properties. Clin Cancer Res (2003) 9:3982S-90S.

7. Marcus R, Davies A, Ando K, Klapper W, Opat S, Owen C, et al. Obinutuzumab for the First-Line Treatment of Follicular Lymphoma. New Engl J Med (2017) 377:1331-44. doi: 10.1056/NEJMoa1614598

8. van Imhoff GW, McMillan A, Matasar MJ, Radford J, Ardeshna KM, Kuliczkowski K, et al. Ofatumumab Versus Rituximab Salvage Chemoimmunotherapy in Relapsed or Refractory Diffuse Large B-Cell Lymphoma: The ORCHARRD Study. J Clin Oncol (2017) 35:544-+. doi: $10.1200 /$ Jco.2016.69.0198
AM, JG, TR and MP, and HK wrote the paper. All authors contributed to the article and approved the submitted version.

\section{FUNDING}

This work was supported by the Department of Protein Engineering and Antibody Technologies at Merck KGaA, Darmstadt and by the Sektion für Stammzell- und Immuntherapie, Universitätsklinikum Schleswig-Holstein, Kiel. This work was funded in part by Deutsche Forschungsgemeinschaft through grant KO 1390/14-1. The funder was not involved in the study design, collection, analysis, interpretation of data, the writing of this article or the decision to submit it for publication.

\section{ACKNOWLEDGMENTS}

We would like to thank the department of Protein Engineering and Antibody Technologies at Merck KGaA and the Section for Stem Cell Transplantation and Immunotherapy at Christian Albrechts University and University Hospital SchleswigHolstein for material and technical support on chemicals and cell-based experiments.

\section{SUPPLEMENTARY MATERIAL}

The Supplementary Material for this article can be found online at: https://www.frontiersin.org/articles/10.3389/fimmu.2020. 560244/full\#supplementary-material

9. Buatois V, Johnson Z, Salgado-Pires S, Papaioannou A, Hatterer E, Chauchet X et al. Preclinical Development of a Bispecific Antibody that Safely and Effectively Targets CD19 and CD47 for the Treatment of B-Cell Lymphoma and Leukemia. Mol Cancer Ther (2018) 17:1739-51. doi: 10.1158/15357163.Mct-17-1095

10. Moskowitz AJ. Optimizing the role of brentuximab vedotin in classical Hodgkin lymphoma therapy. Hematol Am Soc Hematol Educ Program (2018) 2018:207-12. doi: 10.1182/asheducation-2018.1.207

11. Morschhauser F, Flinn I, Advani RH, Diefenbach CS, Kolibaba K, Press OW, et al. Updated results of a phase II randomized study (ROMULUS) of polatuzumab vedotin or pinatuzumab vedotin plus rituximab in patients with relapsed/refractory non-Hodgkin lymphoma. Am Soc Hematol (2014) 32:8519-8519. doi: 10.1182/blood.V124.21.4457.4457

12. Morrison VA. Immunosuppression associated with novel chemotherapy agents and monoclonal antibodies. Clin Infect Diseases (2014) 59:S360-S64. doi: $10.1093 / \mathrm{cid} / \mathrm{ciu} 592$

13. Marafioti T, Hummel M, Foss H-D, Laumen H, Korbjuhn P, Anagnostopoulos I, et al. Hodgkin and Reed-Sternberg cells represent an expansion of a single clone originating from a germinal center B-cell with functional immunoglobulin gene rearrangements but defective immunoglobulin transcription. Blood (2000) 95:1443-50. doi: 10.1182/ blood.V95.4.1443.004k55_1443_1450

14. Kuppers R. Molecular biology of Hodgkin's lymphoma. Adv Cancer Res (2002) 84:278-312. doi: 10.1016/S0065-230X(02)84009-X

15. Seda V. and Mraz M. B-cell receptor signalling and its crosstalk with other pathways in normal and malignant cells. Eur J Haematol (2015) 94:193-205. doi: $10.1111 /$ ejh. 12427 
16. Dal Porto JM, Gauld SB, Merrell KT, Mills D, Pugh-Bernard AE, Cambier J. B cell antigen receptor signaling 101. Mol Immunol (2004) 41:599-613. doi: 10.1016/j.molimm.2004.04.008

17. Ralph DK, Matsen IV FA. Consistency of VDJ rearrangement and substitution parameters enables accurate $B$ cell receptor sequence annotation. PloS Comput Biol (2016) 12:e1004409. doi: 10.1371/ journal.pcbi.1004409

18. Shokat KM, Goodnow CC. Antigen-induced B-cell death and elimination during germinal-centre immune responses. Nature (1995) 375:334. doi: $10.1038 / 375334 \mathrm{a} 0$

19. Bekeredjian-Ding I, Jego G. Toll-like receptors-sentries in the B-cell response. Immunology (2009) 128:311-23. doi: 10.1111/j.1365-2567.2009.03173.x

20. Hatzubai A, Maloney D, Levy R. The use of a monoclonal anti-idiotype antibody to study the biology of a human B cell lymphoma. J Immunol (1981) 126:2397-402.

21. Köhler G, Milstein C. Continuous cultures of fused cells secreting antibody of predefined specificity. Nature (1975) 256:495. doi: 10.1038/256495a0

22. Miller RA, Maloney DG, Warnke R, Levy R. Treatment of B-cell lymphoma with monoclonal anti-idiotype antibody. New Engl J Med (1982) 306:517-22. doi: 10.1056/NEJM198203043060906

23. Torchia J, Weiskopf K, Levy R. Targeting lymphoma with precision using semisynthetic anti-idiotype peptibodies. Proc Natl Acad Sci (2016) 113:537681. doi: $10.1073 /$ pnas. 1603335113

24. Renschler MF, Bhatt RR, Dower WJ, Levy R. Synthetic peptide ligands of the antigen binding receptor induce programmed cell death in a human B-cell lymphoma. Proc Natl Acad Sci (1994) 91:3623-27. doi: 10.1073/ pnas.91.9.3623

25. Greenberg AS, Avila D, Hughes M, Hughes A, McKinney EC, Flajnik MF. A new antigen receptor gene family that undergoes rearrangement and extensive somatic diversification in sharks. nature (1995) 374:168. doi: 10.1038/ $374168 \mathrm{a} 0$

26. Kovaleva M, Ferguson L, Steven J, Porter A, Barelle C. Shark variable new antigen receptor biologics-a novel technology platform for therapeutic drug development. Expert Opin Biol Ther (2014) 14:1527-39. doi: 10.1517/ 14712598.2014.937701

27. Konning D, Zielonka S, Grzeschik J, Empting M, Valldorf B, Krah S, et al. Camelid and shark single domain antibodies: structural features and therapeutic potential. Curr Opin Struct Biol (2017) 45:10-6. doi: 10.1016/ j.sbi.2016.10.019

28. Barelle C, Gill DS, Charlton K. Shark novel antigen receptors-the next generation of biologic therapeutics? Pharm Biotechnol Springer) (2009) 655:49-62. doi: 10.1007/978-1-4419-1132-2_6

29. Camacho-Villegas T, Mata-Gonzalez T, Paniagua-Solis J, Sanchez E, Licea A. Human TNF cytokine neutralization with a vNAR from Heterodontus francisci shark: a potential therapeutic use. MAbs (2013) 5(1):80-5. doi: $10.4161 /$ mabs. 22593

30. Nuttall SD, Humberstone KS, Krishnan UV, Carmichael JA, Doughty L, Hattarki M, et al. Selection and affinity maturation of IgNAR variable domains targeting Plasmodium falciparum AMA1. PROTEINS: Struct Funct Bioinf (2004) 55:187-97. doi: 10.1002/prot.20005

31. Zielonka S, Weber N, Becker S, Doerner A, Christmann A, Christmann C, et al. Shark attack: high affinity binding proteins derived from shark vNAR domains by stepwise in vitro affinity maturation. J Biotechnol (2014) 191:23645. doi: 10.1016/j.jbiotec.2014.04.023

32. Könning D, Zielonka S, Sellmann C, Schröter C, Grzeschik J, Becker S, et al. Isolation of a $\mathrm{pH}$-sensitive IgNAR variable domain from a yeast-displayed, histidine-doped master library. Marine Biotechnol (2016) 18:161-67. doi: 10.1007/s10126-016-9690-z

33. Könning D, Rhiel L, Empting M, Grzeschik J, Sellmann C, Schröter C, et al. Semi-synthetic vNAR libraries screened against therapeutic antibodies primarily deliver anti-idiotypic binders. Sci Rep (2017) 7:9676. doi: 10.1038/ s41598-017-10513-9

34. Meleshko A, Vashkevich K, Fomina E, Scheslenok E, Schkolina T, Sergeev G. Cloning of variable fragments of tumor immunoglobulin, assembling and expressing of human SCFV protein in E. coli for anti-idiotype vaccination. Exp Oncol (2013) 35:8-14.

35. Boder ET, Wittrup KD. Yeast surface display for screening combinatorial polypeptide libraries. Nat Biotechnol (1997) 15:553. doi: 10.1038/nbt0697-553
36. Grzeschik J, Könning D, Hinz SC, Krah S, Schröter C, Empting M, et al. Generation of Semi-Synthetic Shark IgNAR Single-Domain Antibody Libraries. Methods Mol Biol (2018) 1701:147-67. doi: 10.1007/978-1-4939-7447-4_8

37. Benatuil L, Perez JM, Belk J, Hsieh C-M. An improved yeast transformation method for the generation of very large human antibody libraries. Protein Engineering Design Selection (2010) 23:155-59. doi: 10.1093/protein/gzq002

38. Chao G, Lau WL, Hackel BJ, Sazinsky SL, Lippow SM, Wittrup KD. Isolating and engineering human antibodies using yeast surface display. Nat Protoc (2006) 1:755. doi: 10.1038/nprot.2006.94

39. Chen I, Dorr BM, Liu DR. A general strategy for the evolution of bondforming enzymes using yeast display. Proc Natl Acad Sci U S A (2011) 108:11399-404. doi: 10.1073/pnas.1101046108

40. Dickgiesser S, Rasche N, Nasu D, Middel S, Horner S, Avrutina O, et al. SelfAssembled Hybrid Aptamer-Fc Conjugates for Targeted Delivery: A Modular Chemoenzymatic Approach. ACS Chem Biol (2015) 10:2158-65. doi: 10.1021/ acschembio. 5 b00315

41. Peipp M, Lammerts van Bueren JJ, Schneider-Merck T, Bleeker WW, Dechant M, Beyer $\mathrm{T}$, et al. Antibody fucosylation differentially impacts cytotoxicity mediated by NK and PMN effector cells. Blood (2008) 112:2390-9. doi: 10.1182/blood2008-03-144600

42. Carroll W, Yu M, Link M, Korsmeyer S. Absence of Ig V region gene somatic hypermutation in advanced Burkitt's lymphoma. J Immunol (1989) 143:692-98.

43. Watkins B, Davis A, Fiorentini S, Reitz J. V-Region and Class Specific RT-PCR Amplification of Human Immunoglobulin Heavy and Light Chain Genes from B-Cell Lines. Scand J Immunol (1995) 42:442-48. doi: 10.1111/j.13653083.1995.tb03678.x

44. Schmiedel J, Blaukat A, Li SQ, Knochel T, Ferguson KM. Matuzumab binding to EGFR prevents the conformational rearrangement required for dimerization. Cancer Cell (2008) 13:365-73. doi: 10.1016/j.ccr.2008.02.019

45. Bogen JP, Hinz SC, Grzeschik J, Ebenig A, Krah S, Zielonka S, et al. Dual Function $\mathrm{pH}$ Responsive Bispecific Antibodies for Tumor Targeting and Antigen Depletion in Plasma. Front Immunol (2019) 10:1892:1892. doi: 10.3389/fimmu.2019.01892

46. Vuist WM, Levy R, Maloney DG. Lymphoma regression induced by monoclonal anti-idiotypic antibodies correlates with their ability to induce Ig signal transduction and is not prevented by tumor expression of high levels of bcl-2 protein. Blood (1994) 83:899-906. doi: 10.1182/ blood.V83.4.899.bloodjournal834899

47. Toughiri R, Wu X, Ruiz D, Huang F, Crissman JW, Dickey M, et al. Comparing domain interactions within antibody Fabs with kappa and lambda light chains MAbs (2016) 8(7):1276-85. doi: 10.1080/19420862.2016.1214785

48. Zhu D, McCarthy H, Ottensmeier CH, Johnson P, Hamblin TJ, Stevenson FK. Acquisition of potential $\mathrm{N}$-glycosylation sites in the immunoglobulin variable region by somatic mutation is a distinctive feature of follicular lymphoma. Blood (2002) 99:2562-68. doi: 10.1182/blood.V99.7.2562

49. McCann K, Johnson P, Stevenson F, Ottensmeier C. Universal Nglycosylation sites introduced into the B-cell receptor of follicular lymphoma by somatic mutation: a second tumorigenic event? Leukemia (2006) 20:530. doi: 10.1038/sj.leu.2404095

50. Monegal A, Ami D, Martinelli C, Huang H, Aliprandi M, Capasso P, et al. Immunological applications of single-domain llama recombinant antibodies isolated from a naive library. Protein Engineering Design Selection (2009) 22:273-80. doi: 10.1093/protein/gzp002

51. Vincke C, Loris R, Saerens D, Martinez-Rodriguez S, Muyldermans S, Conrath K. General strategy to humanize a camelid single-domain antibody and identification of a universal humanized nanobody scaffold. J Biol Chem (2009) 284:3273-84. doi: 10.1074/jbc.M806889200

52. Briney B, Inderbitzin A, Joyce C, Burton DR. Commonality despite exceptional diversity in the baseline human antibody repertoire. Nature (2019) 566:393-97. doi: 10.1038/s41586-019-0879-y

53. Casi G, Neri D. Antibody-drug conjugates: basic concepts, examples and future perspectives. J Control Release (2012) 161:422-8. doi: 10.1016/ j.jconrel.2012.01.026

54. Zhang L, Fang Y, Yang J, Kopecek J. Drug-free macromolecular therapeutics: Impact of structure on induction of apoptosis in Raji B cells. J Control Release (2017) 263:139-50. doi: 10.1016/j.jconrel.2016.12.025

55. Lim SH, Vaughan AT, Ashton-Key M, Williams EL, Dixon SV, Chan HT, et al. Fc gamma receptor IIb on target B cells promotes rituximab 
internalization and reduces clinical efficacy. Blood (2011) 118:2530-40. doi: 10.1182/blood-2011-01-330357

56. Laventie B-J, Rademaker HJ, Saleh M, de Boer E, Janssens R, Bourcier T, et al. Heavy chain-only antibodies and tetravalent bispecific antibody neutralizing Staphylococcus aureus leukotoxins. Proc Natl Acad Sci (2011) 108:201102265. doi: $10.1073 /$ pnas. 1102265108

57. Zhang J, Li Q, Nguyen T-D, Tremblay T-L, Stone E, To R, et al. A pentavalent single-domain antibody approach to tumor antigen discovery and the development of novel proteomics reagents. J Mol Biol (2004) 341:161-69. doi: 10.1016/j.jmb.2004.05.069

58. Iqbal U, Trojahn U, Albaghdadi H, Zhang J, O'Connor-McCourt M, Stanimirovic D, et al. Kinetic analysis of novel mono-and multivalent VHH-fragments and their application for molecular imaging of brain tumours. Br J Pharmacol (2010) 160:1016-28. doi: 10.1111/j.14765381.2010.00742.x

59. Hofmeyer T, Schmelz S, Degiacomi MT, Dal Peraro M, Daneschdar M, Scrima A, et al. Arranged sevenfold: structural insights into the C-terminal oligomerization domain of human C4b-binding protein. J Mol Biol (2013) 425:1302-17. doi: 10.1016/j.jmb.2012.12.017

60. Shen Z, Liu S, Li X, Wan Z, Mao Y, Chen C, et al. Conformational change within the extracellular domain of $\mathrm{B}$ cell receptor in B cell activation upon antigen binding. Elife (2019) 8:e42271. doi: 10.7554/eLife.42271

61. Abdollahpour-Alitappeh M, Hashemi Karouei SM, Lotfinia M, Amanzadeh A, Habibi-Anbouhi M. A developed antibody-drug conjugate rituximabvcMMAE shows a potent cytotoxic activity against CD20-positive cell line. Artif Cells Nanomed Biotechnol (2018) 46:1-8. doi: 10.1080/21691401. 2018.1449119
62. Mariño E, Grey ST. B cells as effectors and regulators of autoimmunity. Autoimmunity (2012) 45:377-87. doi: 10.3109/08916934.2012.665527

63. Chao MP. Treatment challenges in the management of relapsed or refractory non-Hodgkin's lymphoma-novel and emerging therapies. Cancer Manage Res (2013) 5:251. doi: 10.2147/CMAR.S34273

64. Ku M, Chong G, Hawkes EA. Tumour cell surface antigen targeted therapies in B-cell lymphomas: beyond rituximab. Blood Rev (2017) 31:23-35. doi: 10.1016/j.blre.2016.08.001

65. Shankland KR, Armitage JO, Hancock BW. Non-Hodgkin lymphoma. Lancet (2012) 380:848-57. doi: 10.1016/S0140-6736(12)60605-9

66. Kovalenko OV, Olland A, Piche-Nicholas N, Godbole A, King D, Svenson K, et al. Atypical antigen recognition mode of a shark immunoglobulin new antigen receptor (IgNAR) variable domain characterized by humanization and structural analysis. J Biol Chem (2013) 288:17408-19. doi: 10.1074/ jbc.M112.435289

Conflict of Interest: The authors declare that the research was conducted in the absence of any commercial or financial relationships that could be construed as a potential conflict of interest.

Copyright ๑ 2020 Macarrón Palacios, Grzeschik, Deweid, Krah, Zielonka, Rösner, Peipp, Valerius and Kolmar. This is an open-access article distributed under the terms of the Creative Commons Attribution License (CC BY). The use, distribution or reproduction in other forums is permitted, provided the original author $(s)$ and the copyright owner(s) are credited and that the original publication in this journal is cited, in accordance with accepted academic practice. No use, distribution or reproduction is permitted which does not comply with these terms. 